biological entities remains to be discovered. At the present time the outstanding similarities are morphological and the evolutionary similarities or differences remain to be worked out.

In closing, I should like once again to refer to the Institute. It was obviously in the spirit of fostering a broad academic approach that the Institute of Virology was founded here at the University of Glasgow, and, as I have tried to indicate, the creation of this organization with such adequate housing and equipment, but much more importantly with such able leadership, was a wise and timely move and should be the basis for selfcongratulation on the part of the University. It is certain that the organization will grow with the times, and, as I have indicated, the times seem most propitious.

\section{REFERENCES}

Dulbecco, R. (1961). In Poliomyelitis: Proceedings of Fifth International Polio Congress, 1960, p. 21. Lippincott, Philadelphia and Montreal.

Fraser, K. B. (1959). Virology, 9, 168, 178, 191, 202.

Granoff, A. (1959). Ibid., 9, 636, 649.'

Habel, K. (1962). J. exp. Med., 115, 181

Joklik, W. K., and Darnell, J. E., jun. (1961). Virology, 13, 439.

Principles of Animal Virology (1960), edited by F. M. Burnet, 2nd ed. Academic Press, New York and London.

Simpson, R. W., and Hirst, G. K. (1961). Virology, 15, 436.

Viral and Rickettsial Infections of Man (1959), edited by T. M. Rivers and F. L. Horsfall, jun., 3rd ed. Lippincott, Philadelphia and Montreal.

\title{
SOURCES AND SEQUELAE OF SURGICAL SEPSIS*
}

\author{
BY
}

\author{
JOHN LOEWENTHAL, M.S., F.R.C.S., F.R.A.C.S. \\ Professor of Surgery, University of Sydney, Australia
}

The problem of infection in surgical wounds has always been a contentious one. Lord Lister certainly found it so. From time immemorial the surgeon's attention has, naturally enough, been mainly focused on the drama and challenge of operation, but in recent years he has recognized that the pre-operative preparation and immediate post-operative care of the patient are so integral a part of the operative procedure that the operator himself must assume major responsibility for them. But, in general, the surgeon has been disinclined to concern himself seriously about the "occasional" infected wound. It is rarely lethal, it usually resolves ultimately, complications such as wound herniation may not develop for ages and may then be treated by someone else, and, in any case, it is best handled by his registrar or house-surgeon.

Indisputable evidence exists in all parts of the world that infection of surgical wounds is occurring in either the operating-theatre or wards, that the organism mainly concerned is the Staphylococcus aureus, that the organisms are being born and bred in the hospitals, and that the likelihood is that they will increase in both frequency and possibly virulence. The surgeon's reaction to this has often been mostly one of bland indifference; some surgeons flatly deny that any of their wounds ever become infected. Others admit that sometimes they have a little trouble, but never anything like the horrors that are reported from the professorial unit where this problem is being investigated. But, of course, you have to expect some rather odd things from a professorial unit.

Our interest in this work started some four years ago when we instituted a purely clinical survey of clean surgical wounds. Some 764 of them were carefully scrutinized. They were all uncontaminated wounds which should have healed by first intention, but $8 \%$ of them showed clinical infection (B. P. Morgan, 1958, personal communication).

\section{Findings of a Survey}

More recently a much more intensive survey was undertaken to try to identify the source of the infection. Over a six-months period patients and staff were

* Based on a paper read in the Section of Surgery at the Annual Meeting of the British Medical Association, Auckland, 1961. systematically and intensively investigated clinically and bacteriologically. In brief, our findings (Rountree $e t$ al., 1960) were :

(1) In spite of poor and antiquated operating-theatre facilities with inadequate ventilation there was little evidence that wound infection was initiated in the theatres. During 25 operations 167 nasal swabs were taken from 67 people. In $46 \%$ Staph. aureus was isolated. Of these 67 people, $42 \%$ were carriers on at least one occasion. It is of interest that during the 25 operations the people in the theatre comprised:

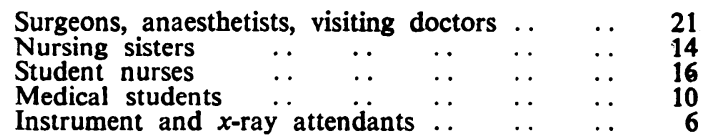

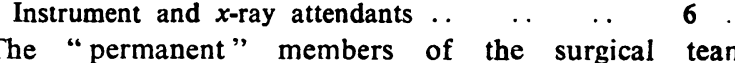
The "permanent" members of the surgical team
numbered nine. Of these nine, six were permanent nasal carriers. However, no patient was apparently infected in the theatre with any of these strains, and it would seem that few of these carriers were dispersers of their organisms, and possibly their strain was not highly virulent. But the potentialities of this situation are considerable under different carrier circumstances.

(2) A total of 217 wounds were intimately examined. "Clean" wounds were those in which no possible reason for contamination was present. A cross-infection rate of $14 \%$ occurred in "clean " wounds and $68 \%$ in "dirty" wounds (Table I).

\begin{tabular}{|c|c|c|c|}
\hline Wound & No. of Cases & Uninfected & Infected \\
\hline $\begin{array}{ll}\text { Clean } & \ldots \\
\text { Dirty } & \ldots\end{array}$ & $\begin{array}{r}198 \\
19\end{array}$ & $\begin{array}{r}171 \\
6\end{array}$ & $\begin{array}{l}27(14 \%) \\
13(68 \%)\end{array}$ \\
\hline Total .. & 217 & 177 & $40(18 \%)$ \\
\hline
\end{tabular}

(3) The site of the wound on the body or the sex of the patient did not significantly affect the infection rate, nor was it influenced greatly by the surgeon. However, the type of dressing did. Gauze pads which absorbed blood, serum, or sweat and required early post-operative changing werc associated with a much higher incidence of wound infection than when a spray-on plastic seal ("healex" or "nobecutane") was used. While $61 \%$ of wounds were infected under a gauze pad, only $7 \%$ were when sealed (Table II).

(4) Of 40 wounds showing cross-infection, $35(87 \%)$ were infected with Staph. aureus, either alone or with other organisms. The predominant staphylococcus present in $60 \%$ of wounds was phage type 47, which is resistant to penicillin streptomycin, tetracyclines, and usually chloramphenicol and 
TABLE II.-Relation of Infection to Type of Dressing

\begin{tabular}{c|c|c|c}
\hline Type of Dressing & No. of Cases & Uninfected & \multicolumn{1}{|c}{ Infected } \\
\cline { 2 - 4 } Plastic seal .. & 171 & 159 & $12(7 \%)$ \\
Gauze pad: & 27 & 12 & $15(56 \%)) 61 \%$ \\
Clean wound & 19 & 6 & $13(68 \%)\}$ \\
\hline Dirty,. & 217 & 177 & $40(18 \%)$ \\
\hline Total .. & 19 & \\
\hline
\end{tabular}

erythromycin. These strains have been present in the hospital since 1951 (Rountree and Thomson, 1952) and have been the chief cross-infecting organisms in surgical wounds.

(5) Review of ward conditions showed them to be heavily contaminated with staphylococci. The organism was recovered in large numbers - and repeatedly-from the dust on floors and furniture, dressing-trolleys, the aprons and caps of nurses, blankets, etc. Not unexpectedly, therefore, the noses of patients were found to become extensively colonized. They were swabbed on admission and weekly afterwards. Some $10 \%$ of the noses of patients and $6 \%$ of those of staff were found to acquire staphylococci each week (Table III). The effect of this may be seen in Table IV.

TABLE III.-Staph. aureus in Noses Swabbed Weekly

\begin{tabular}{|c|c|c|c|}
\hline & & Patients & Staff \\
\hline $\begin{array}{l}\text { Weekly swabs taken } \\
\text { Positive swabs } \\
\text { Loss of strains } \\
\text { Acquisition of strains } \\
\text { Type } 47 \text { present } \\
\text { " 80/81 \# }\end{array}$ & $\begin{array}{l}\because \\
\because \\
\because \\
\therefore\end{array}$ & $\begin{array}{l}854 \\
403(48 \%) \\
34(4 \%) \\
84(10 \%) \\
118(14 \%) \\
40(5 \%)\end{array}$ & $\begin{array}{l}456(40 \%) \\
182(40 \%) \\
25(5 \%) \\
27(6 \%) \\
36(8 \%) \\
21(5 \%)\end{array}$ \\
\hline
\end{tabular}

TABle IV.-Nasal Carrier Rates of Staph. aureus in Patients with No Operation, with Uninfected Wounds, or with Infected Wounds

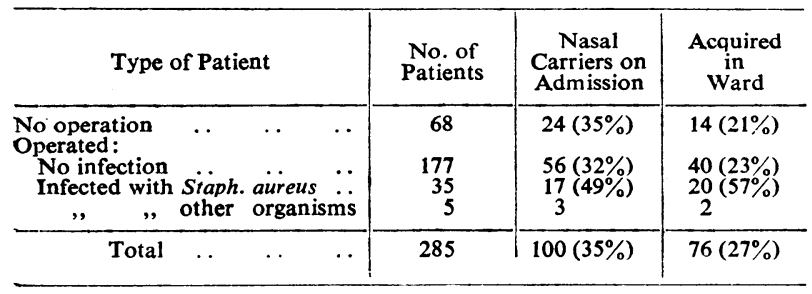

(6) The assessable consequences of infection were considerable. At least one death could be directly attributable to wound infection. In two cases wound disruption occurred (Table V).

TABLE V:-Consequences of Infection in 40 Patients

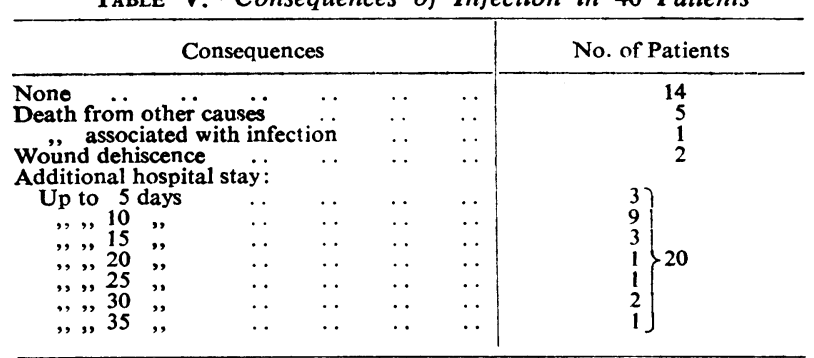

Comparing the length of stay of patients with infected wounds with the average in this unit having the same type of surgical complaint and grouping them in five-day increments, it will be seen that 290 patient days were lost - that is, about $5 \%$ of the bed strength.

The measures designed to combat the menace of cross-infection are being widely studied. While the findings of investigators, wherever they are working, are in substantial agreement, the interpretation of the findings is greatly hampered by our ignorance of certain basic factors. For instance, no adequate tests exist for the pathogenicity of the staphylococcus, so the true significance of colonization of patients' noses cannot be fully assessed. How long do the organisms remain virulent in the carrier state and in the ward environment? What are the factors concerned in the dispersal of staphylococci from the nose? What is the route of transfer from nose to wound-is it by droplet, by direct continuity with the skin, or through inanimate objects such as blankets? What part does perineal contamination play? The answer to these and many other similar questions is at present unknown.

The attack on such a vague enemy, if it is to have a reasonable chance of success, may require new thinking on such basic matters as the design of our hospitals. In Sydney we are having the opportunity to do this. A new professorial block is being built, in which the planning has been directed to eliminate crossinfection - to the limit of our present knowledge. It has been designed by the N.S.W. Government Architect, Mr. E. H. Farmer, and by me without the benefit of any committee. It comprises ward-nursing units for the professors of medicine and surgery, four operatingtheatres with ancillaries, and a central sterile supply department. It will be ready for occupation during May, 1962.

The measures taken specifically to reduce infection are as follows.

\section{Theatre Suite}

The four operating-theatres are isolated by an air-lock (Fig. 1). Both patients and staff must change completely on entering and leaving the theatres. Patients are transferred from the ward to the anaesthetic trolley in the air-lock and, of course, linen and blankets are changed at this point. Staff enter their change-rooms on the outside of the lock and, after changing, enter on the inside of it.

Ventilation is arranged at a high level of 17 changes an hour, with the flow of air so arranged that it passes primarily from the theatres, where there is a slight positive pressure, through the anaesthetic-rooms and out through the air-lock, so that the current at this point is always from theatres outwards. Cross-currents from the theatres have been avoided by exhausting the intervening rooms so that cross-contamination from a "dirty" case in one theatre to a "clean" case in another theatre is avoided. It is considered that a "dirty" theatre is an anachronism: the provisions for asepsis should be such that any degree of cross-infection can be safely handled.

The provision of ventilating equipment sufficient to handle such a large volume of air in itself creates a problem. None of the air can be recirculated; it has to be dehumidified to $50 \%$ in a climate where it may reach approximately $100 \%$, cooled to $70^{\circ} \mathrm{F}$. $\left(21.1^{\circ} \mathrm{C}\right.$.) in summer or warmed in winter, filtered both by an electronic precipiton and by a mesh filter, made to flow in the right directions, and arranged in duplicate plants so that when only one set of theatres is in use half the equipment can be switched off and adequate maintenance carried out.

In the belief that absolute physical cleanliness is required, the theatres have been designed so that they can be thoroughly hosed out at the end of each day's work. This requirement has necessitated special recessed waterproofed power outlets and a hard 
impermeable jointless wall finish. This is a spray-on plastic.

All instruments will be prepacked, autoclaved, and delivered direct to the theatres by service lift from the central sterile supply department. After use they are rough-cleaned and, together with all dressings and drapes, removed from the suite as soon as possible by a scparate service lift. Both lift shafts are exhaustventilated.

Inside the air-lock an intensive nursing unit of four beds is provided for the intimate care of certain major operation cases-but not all cases. It is felt that only a small minority of cases require this detailed supervision and that the surgeon and anaesthetist are the ones to direct it-not the junior house-surgeon who does so under our present circumstances. The unit has therefore been sited so that both surgeon and anaesthetist can continue operating on further patients during the recovery phase of the difficult case, which universally takes pride of place at the beginning of an operating-list. This area has an entirely separate ventilating unit designed so that there will be no back-leak of air into the main theatre zone.

\section{Wards}

The design of the wards has been influenced by the requirement that they should be available for use by either one sex or both sexes, or that heavy and light cases can occupy different areas.

Precautions to prevent cross-infection include: (1) A ward treatment room where all dressings are done with individual dressing-trays provided from the central sterile supply department. This room has a separate ventilating equipment giving four to five changes an hour. Clearly, without this essential provision such an area becomes a source of potential danger rather than of safety, but hospitals . are still being built without it. (2) By simple partitioning of some ward beds and providing an efficient exhaust fan nasal

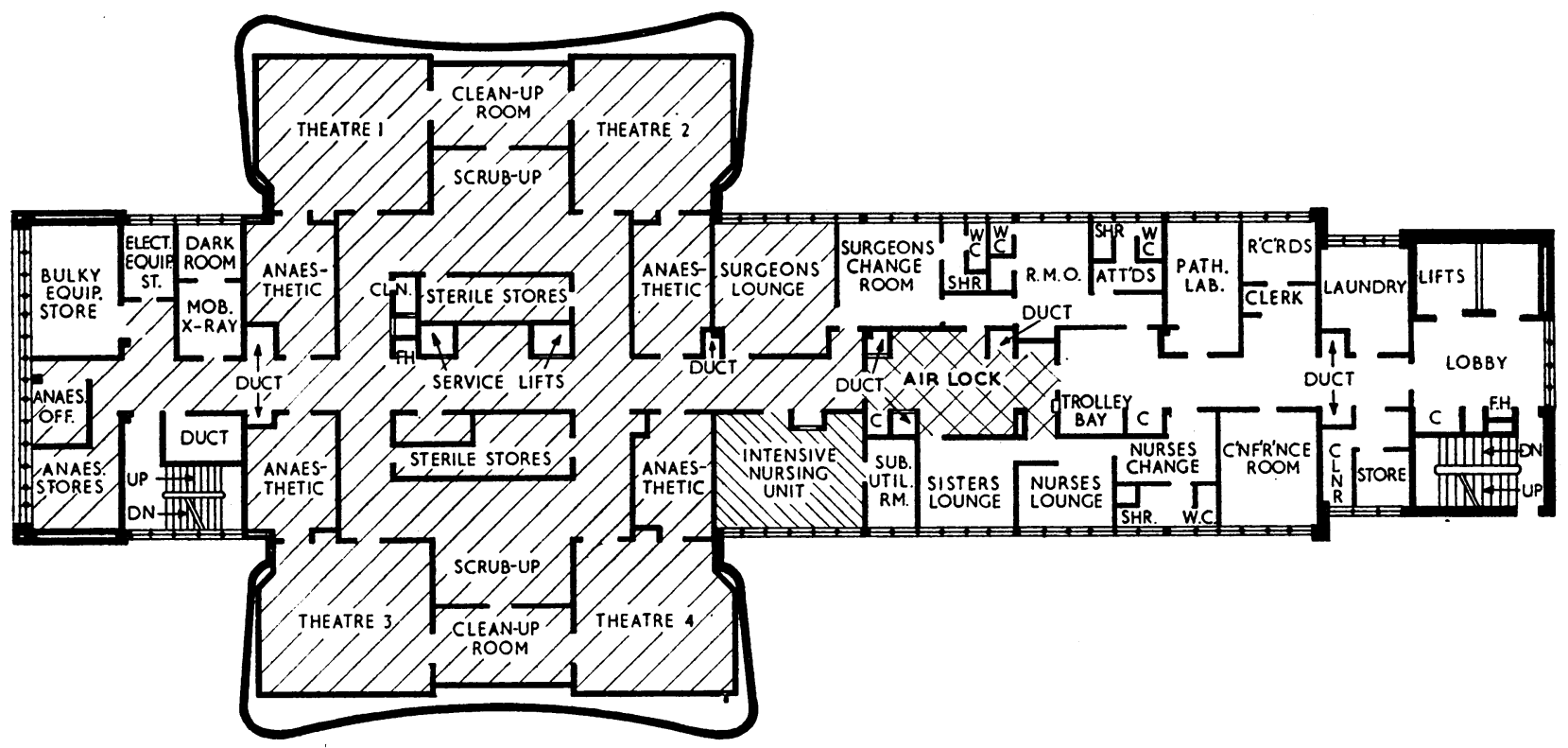

Fig. 1.-Theatre-floor plan of the Royal Prince Alfred Hospital, Camperdown, New South Wales, professorial block.

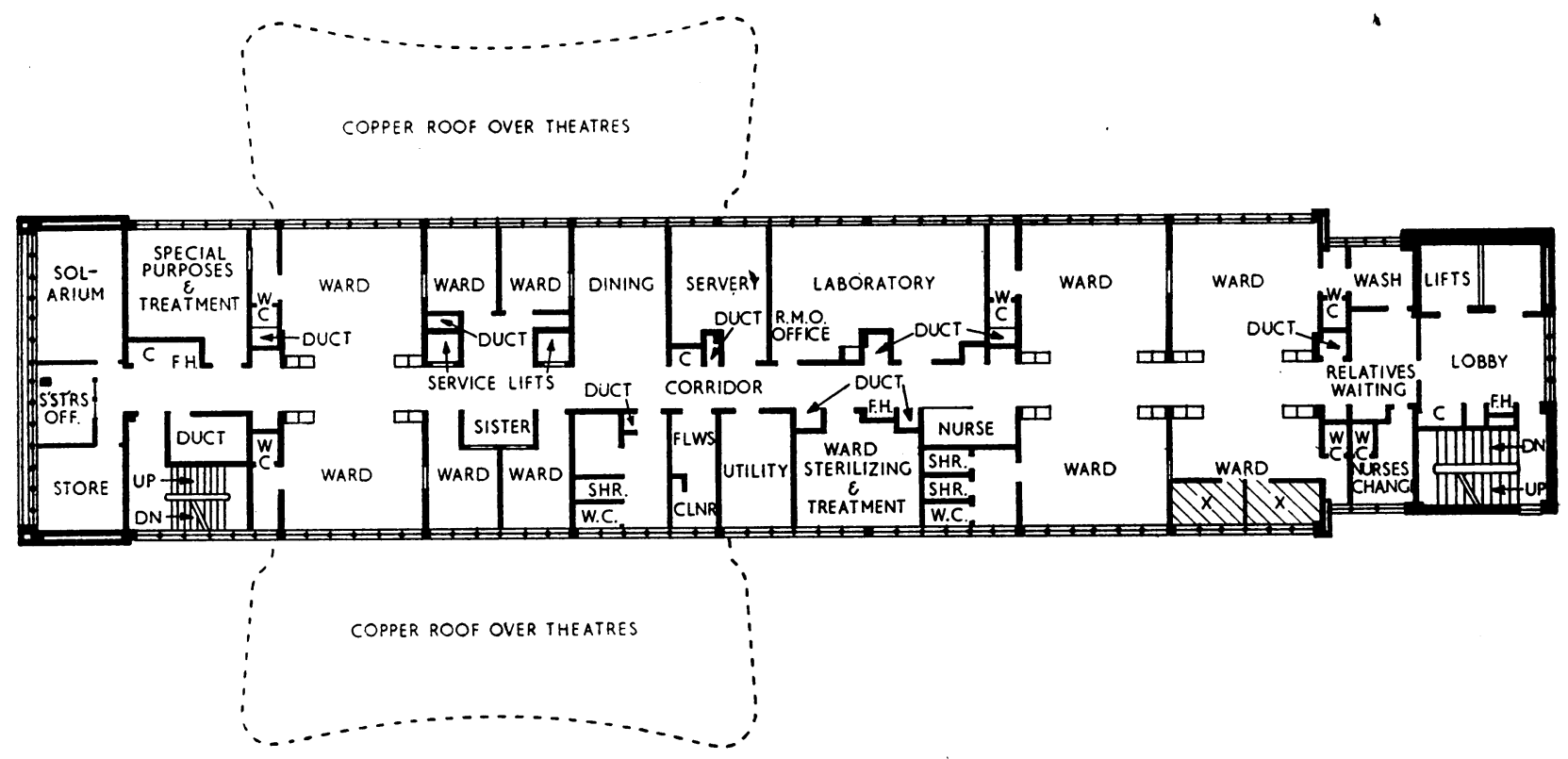

FIG. 2.-Second-floor plan. 
staphylococcal carriers can be effectively isolated. Four single rooms are provided on this plan, and it was suggested that these should be used for segregating carriers. However, these rooms are for the use of the seriously ill, and the nasal carriers are usually well patients who may not require operation as part of their treatment. (3) Each four-bedded unit is provided with its own toilet and basin. They also have a self-closing door and are exhaust-ventilated.

The results of this type of planning are yet to be observed. The baseline has been established over some two and a half years and the incidence of wound infection, cross-infections, and the trends in them have been recorded. The same system of observation will continue when the new block is used, and an accurate comparison should be possible. This will be of value in indicating the effectiveness of the overall planning, but, unfortunately, it will not help in elucidating the present most pressing problem-What is the comparative importance of the various measures necessary to deal effectively with staphylococcal cross-infection; which ones are major and mandatory and which are minor but desirable? Until these are known our attack is unfortunately diffuse and dispersed, and the inclination to deal with the problem by ignoring it can go largely unchallenged.

\section{Summary}

A detailed survey of wound infection in a surgical unit in Sydney strongly suggests that infection is mainly occurring in the wards. Spray-on plastic dressings have been helpful in reducing the infection rate.

Extensive colonization with staphylococci of the noses of patients and staff were observed. Weekly rates of colonization were: patients $10 \%$, staff $6 \%$. Nasal staphylococcal carriers showed a woundinfection rate double that of those whose noses were clear, and as a result had a higher morbidity and a longer hospital stay.

Such observations require changes in the physical planning of hospitals, and the broad principles of such a plan are suggested.

A most useful grant for work on wound infection from the Post-Graduate Committee in Medicine of the University of Sydney is gratefully acknowledged.

\section{REFERENCES}

Rountree, P. M., Harrington, M., Loewenthal, J., and Gye, R. (1960). Lancet. 2, 1. (1952). Ibid., 2, 262.
and Thomson. E. F. (19)

\footnotetext{
"Was a hunting accident the cause of Sir Charles Hastings's choice of medicine as a career? This was the theory presented by Canon J. S. Leatherbarrow. Rector of Martley, at [a] meeting of Worcestershire Archaeological Society. In a paper on the Hastings family. who occupied the living of Martley for 150 years, and provided excellent examples of the squire-cum-parson, or 'squarson' of the nineteenth century, Mr. Leatherbarrow told members of an incident which took place when Charles was 12 . His father, the Reverend James Hastings, was thrown from his horse and wandered home dazed and in a state of mind which made him a near-lunatic for 50 years. The rector entered the house and sat on the bottom of the stairs. It was Charles who succeeded in persuading him to go to bed, and it is possible that the experience either created or extended an interest in medicine that eventually made Sir Charles one of the greatest surgeons of all time." (Berrow's Worcester Journal, April 6.)
}

\section{PLACE OF SURGERY IN EARLY STAGES OF ACUTE OSTEOMYELITIS}

BY

NIGEL H. HARRIS, M.B., F.R.C.S.

From the Royal National Orthopaedic Hospital, London

\section{[With Special Plate]}

Sir Robert Hutchison once said, "Be not the first by whom the new is tried, nor yet the last to lay the old aside." These words are relevant, for as new and powerful antibiotics become available there may be a tendency to lose sight of the value of surgery-a longestablished method of treatment.

It is certainly true that most patients with acute osteomyelitis are cured with antibiotics alone if these are given early enough - that is, in the first three days of the illness-and for a long enough time; few would disagree that drainage of the abscess (whether by open operation or aspiration) plays an important part in the treatment of many of the patients by the time they are admitted to hospital. F.owever, there is no general agreement on the timing of drainage, or on the relative merits of aspiration and open drainage. This paper is principally concerned with these two aspects, and is based on a study of 84 unselected patients ; 45 of them, seen at Fulham Hospital, London, have been reviewed elsewhere (Harris, 1960), but only brief reference was made to the place of surgery in treatment. Most of the remaining 39 patients have been seen at the Royal National Orthopaedic Hospital, and a few at other hospitals in the London area.

Detailed antibiotic therapy will not be discussed in this paper; it has played, and continues to play, a vital role in the management of acute osteomyelitis, but the relative merits of antibiotics and surgery could be decided only by a carefully controlled clinical trial, and this is ethically undesirable.

\section{Pathological Basis for Early Surgical Drainage}

Early operation is based mainly on the fact that certain important pathological changes occur in the bone during the first few days of the illness. These changes will be described briefly.

By the second or third day, in the classic acute type of illness, pus has formed, the periosteum is raised over a variable extent, and the vascular supply has become compromised; the pus is under considerable pressure, and if this is not relieved thrombosis of vessels may occur, leading inevitably to some degree of bone necrosis. Early and complete decompression of the bone before the blood-supply is interrupted will prevent or reduce this necrosis. It is unfortunate, therefore, that the story of the disease has been written (because of late diagnosis) by the time many of the patients are admitted to hospital.

Trueta and Morgan (1954), in describing these early pathological changes, made this significant statement: "Penicillin alone cannot prevent bone changes occurring after the blood-supply is interrupted; early surgery is just as necessary now as in pre-penicillin times." This advice is still relevant and applies to all antibiotics.

\section{Causative Organism}

The coagulase-positive staphylococcus is by far the most commonly isolated organism, and a high incidence of penicillin-resistant staphylococci has been reported in 